\section{Single port paediatric heminephrouretectomy}

\author{
Simon Blackburn, Vanessa Chow, \\ Varadarajan Kalidasan, \\ Anies Mahomed
}

Royal Alexandra Childrens' Hospital, Brighton, UK

\begin{abstract}
We present a 4-year-old girl who underwent a single incision laparoscopic surgery (SILS) heminephrouretectomy. The procedure was completed without intra-operative complications or conversion. The operative time was $162 \mathrm{~min}$. At 3 month follow up there is no evident scar and the patient is asymptomatic. SILS upper moiety heminephrouretectomy for duplex kidney is safe and technically feasible in children.
\end{abstract}

\section{Introduction}

The potential advantages of reduced analgesic requirement and improved cosmesis make single incision laparoscopic surgery (SILS) an exciting innovation. We present a child with a duplex left kidney and associated incontinence, who underwent SILS heminephrouretectomy.

\section{Case Report}

A 4-year-old girl presented with persistent urinary dribbling and urinary tract infections. An ultrasound demonstrated a left duplex kidney. A MAG3 renogram confirmed poor function in the left upper moiety (13\% function). Delayed views demonstrated a dilated, tortuous, ureter subtending the upper moiety. A decision was taken to perform a SILS left upper pole heminephrouretectomy.

\section{Operative technique}

The patient was placed in a 45-degree right lateral position and a SILS (Covidien plc, Dublin, Ireland) port placed. Pneumoperi toneum was maintained at $12 \mathrm{mmHg}$.

The descending colon was reflected and the splenic flexure left in place, exposing the left kidney. The anterior aspect of the kidney was exposed to reveal the junction of the upper and lower poles (Figure 1). Dissection proceeded medially to expose the pelvis of the upper pole moiety and the hilar structures.
Both ureters where then identified downstream from the pelvis and the upper pole ureter transected (Figure 2). Dissection of the upper pole ureter allowed its delivery from underneath the lower pole hilar vessels. Traction on the ureter and pelvis then facilitated dissection of the limits of the upper pole.

The upper pole vessels were divided using an ultrasonic dissector. Vascular demarcation of the poles defined the line of parenchymal division, which was accomplished using an ultrasonic dissector. The distal ureter was dissected distally before ligation and division. The upper pole was removed through the umbilical incision. No drains were placed. The child was discharged on the second postoperative day. An ultrasound at 2 weeks confirmed a viable lower pole. The patient is currently dry and has no visible scarring (Figure 3).

\section{Discussion}

Minimal access renal surgery in children has evolved since the first laparoscopic nephrectomy was reported by Koyle et al. in 1993. ${ }^{1}$ This was shortly followed by the first report of laparoscopic heminephrectomy in a child. ${ }^{2}$ Whilst uptake of laparoscopic or retroperitoneoscopic nephrectomy in paediatric practice has been rapid, application of these techniques to heminephrectomy has been slower. ${ }^{3}$ This is, perhaps, because of the lower frequency of this operation, the younger patient population and the potential for more serious complications; including urinoma, haematoma and ischaemia of the remaining renal parenchyma. ${ }^{4}$ There are, however, potential advantages from the laparoscopic technique, particularly the precise division of the kidney offered by magnification from the laparoscope. ${ }^{5}$ Laparoscopy also facilitates dissection of the vascular pedicle without mobilisation of the kidney, thus potentially decreasing the risk of ischaemia to the remaining renal tissue. ${ }^{6}$

Laparoscopic heminephrectomy has been accomplished both retroperitoneally and transperitoneally. The transperitoneal route offers a larger working space, familiarity with anatomical landmarks and easy access to the distal ureter ensuring adequate removal. Recovery from surgery is as rapid as with other approaches and post operative adhesion formation has not been demonstrated to be a significant problem. ${ }^{7,8}$

Traxel et al. recently reviewed 5 comparative studies of open versus laparoscopic partial nephrectomy in children. ${ }^{6,9-13}$ They comment on an increased operating time with laparoscopic surgery, although a trend was observed towards a decrease with increasing experience. Length of stay was shorter in all studies
Correspondence: Anies Mahomed, Royal Alexandra Childrens' Hospital, Eastern Road, Brighton, BN2 5BE, UK.

E-mail: anies.mahomed@bsuh.nhs.uk

Key words: single incision laparoscopic surgery, heminephrectomy, duplex kidney, pediatric.

Conflict of interest: the authors report no conflicts of interest.

Contributions: SB, patient's operation and initial manuscript draft; VC, manuscript draft; VK, patient management and patient's operation; AM, patient's operation and manuscript revision.

Received for publication: 22 June 2011.

Accepted for publication: 29 August 2011.

This work is licensed under a Creative Commons Attribution NonCommercial 3.0 License (CC BYNC 3.0).

(C) Copyright S. Blackburn et al., 2011

Licensee PAGEPress, Italy

Surgical Techniques Development 2011; 1:e18

doi:10.4081/std.2011.e18

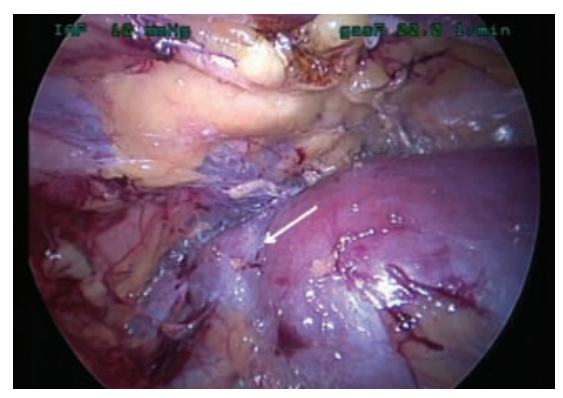

Figure 1. Intraoperative view of anterior aspect of left duplex kidney showing upper and lower pole interface. (arrowed)

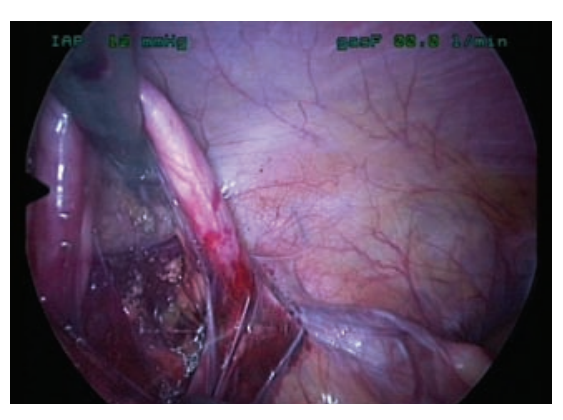

Figure 2. Isolated dilated ureter of upper moiety prior to division.

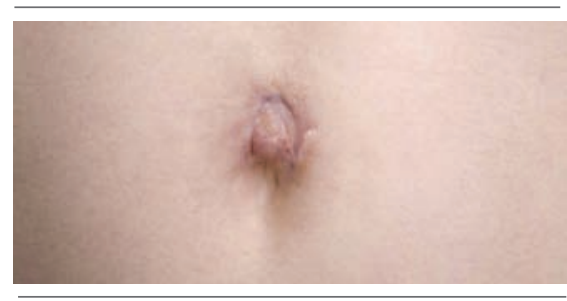

Figure 3. Clinical photograph of the patient, showing the umbilical wound 2 weeks after surgery. 
and the majority demonstrated a decrease in analgesic requirement. Of particular note is that some patients undergoing open surgery required a second incision to remove the distal ureter. ${ }^{11}$ SILS has the potential to offer further advantages over a three port laparoscopic approach, especially in terms of cosmesis and reduced postoperative pain. SILS has gained popularity in adult practice over recent years and has started to be employed in paediatric urology, having been applied to varicocelectomy, nephrectomy, pyeloplasty and nephrouretectomy. ${ }^{14-16}$ Jeon et al. recently described a single port lower pole heminephrectomy for a patient with a $3.5 \mathrm{~cm}$ lower pole metanephric adenoma. ${ }^{17}$ We believe our case to be the first description of a SILS upper pole heminephrouretectomy for a child with a duplex kidney. Although the lack of triangulation poses challenges, these are not insurmountable and the upper moiety and ureter can be excised without technical difficulty or risk to the viability of the lower pole. Conventional, reusable, straight laparoscopic instrument are more than adequate to the task and there is no absolute requirement for expensive articulated devices. In common with our previous experience of transperitoneal laparoscopic heminephrectomy and in contrast to some authors' descriptions, splenic mobilisation was not necessary to dissect the upper pole. ${ }^{7,818}$ This reduces the risk of splenic injury. This procedure was accomplished in a slightly longer operative time than our previous experience with transperitoneal laparoscopic heminephrectomy. ${ }^{7}$ We believe this will, however, be modified downwards as more experience is gained. The use of straight instruments greatly ameliorates the cost implications of the single port procedure, given that the only additional equipment is that of the SILS port. By our estimates the cost of the SILS port is offset by the cost of 3 disposable ports, which is, what is routinely required for a standard laparoscopic heminephrectomy. If a $4^{\text {th }}$ port is necessary, as is sometime the case, then costs would move in favour of the SILS approach.

\section{Conclusions}

We have described what we believe to be the first SILS upper pole heminephrouretectomy and demonstrate its feasibility in paediatric practice. The potential advantages of reduced analgesic requirement and improved cosmesis make this an exciting development in paediatric urology. Further studies are, however, required to further investigate the advantages of this technique.

\section{References}

1. Koyle MA, Woo HH, Kavoussi LR. Laparoscopic nephrectomy in the first year of life. J Pediatr Surg 1993;28:693-5.

2. Jordan GH, Winslow BH. Laparoendoscopic upper pole partial nephrectomy with ureterectomy. J Urol 1993;150:940-3.

3. Valla JS, Breaud J, Carfagna L, et al. Treatment of ureterocele on duplex ureter: upper pole nephrectomy by retroperitoneoscopy in children based on a series of 24 cases. Eur Urol 2003;43:426-9.

4. Valla JS. Retroperitoneoscopic surgery in children. Semin Pediatr Surg 2007;16:270-7.

5. Janetschek G, Seibold J, Radmayr C, Bartsch G. Laparoscopic heminephroureterectomy in pediatric patients. J Urol 1997;158:1928-30.

6. El-Ghoneimi A, Farhat $\mathrm{W}$, Bolduc $\mathrm{S}$, et al. Retroperitoneal laparoscopic vs open partial nephroureterectomy in children. BJU Int 2003;91:532-5.

7. Mahomed A. Technique of laparoscopic transperitoneal lower pole heminephroureterectomy. J Laparoendosc Adv Surg Tech A 2009;19 Suppl 1:S201.
8. Mahomed AA, Hoare C, Welsh F, Driver CP. A two-center experience with the exclusive use of laparoscopic transperitoneal nephrectomy for benign renal disease in children. Surg Endosc 2007;21:1532-6.

9. Robinson BC, Snow BW, Cartwright PC, et al. Comparison of laparoscopic versus open partial nephrectomy in a pediatric series. J Urol 2003;169:638-40.

10. Lee RS, Retik AB, Borer JG, et al. Pediatric retroperitoneal laparoscopic partial nephrectomy: comparison with an age matched cohort of open surgery. J Urol 2005;174:70811.

11. Piaggio L, Franc-Guimond J, Figueroa T, et al. Comparison of laparoscopic and open partial nephrectomy for duplication anomalies in children. J Urol 2006;175:2269-73.

12. Chertin B, Ben-Chaim J, Landau EH, et al. Pediatric transperitoneal laparoscopic partial nephrectomy: comparison with an agematched group undergoing open surgery. Pediatr Surg Int 2007;23:1233-6.

13. Traxel EJ, Minevich EA, Noh PH. A review: the application of minimally invasive surgery to pediatric urology: upper urinary tract procedures. Urology 2010;76:122-33.

14. Kaouk JH, Palmer JS. Single-port laparoscopic surgery: initial experience in children for varicocelectomy. BJU Int 2008; 102:97-9.

15 Bayazit Y, Aridogan IA, Abat D, et al. Pediatric transumbilical laparoendoscopic single-site nephroureterectomy: initial report. Urology 2009;74:1116-9.

16. Desai MM, Berger AK, Brandina R, et al. Laparoendoscopic single-site surgery: initial hundred patients. Urology 2009;74: 805-12.

17. Jeon HG, Kim DS, Jeoung HB, et al. Pediatric laparoendoscopic single-site partial nephrectomy: initial report. Urology 2010;76:138-41.

18. Breda A, Lam JS, Veale J, et al. Laparoscopic heminephrectomy for upper-pole moiety in children using a 3-mm laparoscope and instruments. J Endourol 2007;21:883-5. 